\title{
POWER DOMINATION IN KNÖDEL GRAPHS AND HANOI GRAPHS
}

\author{
Seethu Varghese \\ A. ViJAYAKUMAR \\ Department of Mathematics \\ Cochin University of Science and Technology \\ Cochin-682022, India \\ e-mail: seethu333@cusat.ac.in \\ vijay@cusat.ac.in \\ AND \\ AndReas M. Hinz \\ Department of Mathematics \\ Ludwig-Maximilians-Universität München \\ 80333 Munich, Germany \\ and \\ Institute for Mathematics, Physics, and Mechanics \\ 1000 Ljubljana, Slovenia \\ e-mail: hinz@math.lmu.de
}

\begin{abstract}
In this paper, we study the power domination problem in Knödel graphs $W_{\Delta, 2 \nu}$ and Hanoi graphs $H_{p}^{n}$. We determine the power domination number of $W_{3,2 \nu}$ and provide an upper bound for the power domination number of $W_{r+1,2^{r+1}}$ for $r \geq 3$. We also compute the $k$-power domination number and the $k$-propagation radius of $H_{p}^{2}$.
\end{abstract}

Keywords: domination, power domination, Knödel graph, Hanoi graph.

2010 Mathematics Subject Classification: 05C69.

\section{REFERENCES}

[1] A. Aazami, Domination in graphs with bounded propagation: algorithms, formulations and hardness results, J. Comb. Optim. 19 (2010) 429-456.

doi:10.1007/s10878-008-9176-7 
[2] T.L. Baldwin, L. Mili, M.B. Boisen Jr. and R. Adapa, Power system observability with minimal phasor measurement placement, IEEE Trans. Power Systems 8 (1993) $707-715$. doi: $10.1109 / 59.260810$

[3] J.-C. Bermond, H.A. Harutyunyan, A.L. Liestman and S. Perennes, A note on the dimensionality of modified Knödel graphs, Internat. J. Found. Comput. Sci. 8 (1997) 109-116. doi:10.1142/S0129054197000094

[4] G.J. Chang, P. Dorbec, M. Montassier and A. Raspaud, Generalized power domination of graphs, Discrete Appl. Math. 160 (2012) 1691-1698. doi:10.1016/j.dam.2012.03.007

[5] P. Dorbec, M.A. Henning, C. Löwenstein, M. Montassier and A. Raspaud, Generalized power domination in regular graphs, SIAM J. Discrete Math. 27 (2013) $1559-1574$. doi: $10.1137 / 120891356$

[6] P. Dorbec and S. Klavžar, Generalized power domination: propagation radius and Sierpiński graphs, Acta Appl. Math. 134 (2014) 75-86. doi:10.1007/s10440-014-9870-7

[7] P. Dorbec, M. Mollard, S. Klavžar and S. Špacapan, Power domination in product graphs, SIAM J. Discrete Math. 22 (2008) 554-567. doi:10.1137/060661879

[8] M. Dorfling and M.A. Henning, A note on power domination in grid graphs, Discrete Appl. Math. 154 (2006) 1023-1027. doi:10.1016/j.dam.2005.08.006

[9] G. Fertin and A. Raspaud, A survey on Knödel graphs, Discrete Appl. Math. 137 (2004) 173-195. doi:10.1016/S0166-218X(03)00260-9

[10] T.W. Haynes, S.M. Hedetniemi, S.T. Hedetniemi and M.A. Henning, Domination in graphs applied to electric power networks, SIAM J. Discrete Math. 15 (2002) 519-529. doi:10.1137/S0895480100375831

[11] M.C. Heydemann, N. Marlin and S. Pérennes, Cayley graphs with complete rotations, Research Report INRIA 3624 (1999).

[12] A.M. Hinz, The Tower of Hanoi, Enseign. Math. (2) 35 (1989) 289-321.

[13] A.M. Hinz, S. Klavžar, U. Milutinović and C. Petr, The Tower of Hanoi-Myths and Maths (Springer, Basel, 2013).

[14] A.M. Hinz, S. Klavžar and S.S. Zemljič, A survey and classification of Sierpińskitype graphs, Discrete Appl. Math. 217 (2017) 565-600. doi:10.1016/j.dam.2016.09.024

[15] W. Knödel, New gossips and telephones, Discrete Math. 13 (1975) 95. doi:10.1016/0012-365X(75)90090-4 
[16] F.T. Leighton, Introduction to Parallel Algorithms and Architectures: Arrays, Trees, Hypercubes (Morgan Kaufman, San Francisco CA, 1992).

[17] J.-H. Park and K.-Y. Chwa, Recursive circulant: a new topology for multicomputers networks, in: Proc. Int. Symp. Parallel Architectures, Algorithms and Networks (1994) $73-80$.

doi:10.1109/ISPAN.1994.367162

[18] S. Varghese and A. Vijayakumar, On the power domination number of graph products, Lecture Notes in Comput. Sci. 9602 (2016) 357-367. doi:10.1007/978-3-319-29221-2_31

[19] M. Zhao, L. Kang and G.J. Chang, Power domination in graphs, Discrete Math. 306 (2006) 1812-1816.

doi:10.1016/j.disc.2006.03.037

Received 19 January 2016

Revised 2 September 2016

Accepted 27 September 2016 